\title{
Antimicrobial Activities of Extracts Derived from in vivo and in vitro Grown Trifolium pratense (Red clover)
}

\author{
Arash Khorasani Esmaeili, Rosna Mat Taha, Behrooz Banisalam, Sadegh Mohajer, and Noor Zalina \\ Mahmood
}

\begin{abstract}
Antimicrobial efficiency of extracts derived from Trifolium pratense (in vivo and in vitro grown plants, including callus) were examined using ethanol and methanol as solvents and tested against four bacterial pathogens (two gram negative and two gram positive) and three fungal pathogens. The antimicrobial activity of the methanol extract was found to give higher inhibition zone when compared with ethanol extract. Among the callus, in vitro and in vivo grown plants, the callus extract showed better antimicrobial activity, thus revealing a new potential use of callus of Trifolium pretense.
\end{abstract}

Index Terms-Antimicrobial, Callus, in vitro, Trifolium pratense

\section{INTRODUCTION}

The use of medicinal plants as a source of antimicrobial can be traced back over five millennia. Plants are rich source of effective and safe medicines that often used in the treatment of various ailments. There are many published reports from different parts of the world on the antimicrobial properties of medicinal plants, and as a result, plants are still recognized as the bedrock for modern medicine to treat infectious diseases [1], [2]. Trifolium pratense L. is a versatile forage legume which is widely used and commonly known as Red clover [3].

Red clover belongs to the Fabaceae family that has been known for many countries as important forage plants and valuable herbs in folk medicine. The Fabaceae family comprises of about 240 species of clovers, occurring in temperate and subtropical regions of both hemispheres. Among all clovers, Red clover is the best known clover that is being used for the production of herbal medicines, and alternative to the conventional hormonal replacement therapy [4], [5].

Many reports have shown that Red clover is a rich source of isoflavones (plant based chemicals that act like estrogens in the body). The majority of the studies on the biological properties of Red clover and is focused on its phytoestrogenic action, being a result of isoflavone content [6].

Red clover has been used in traditional medicine by different cultures. For example, in Turkish folk medicine, Red clover has been used for its expectorant, analgesic and antiseptic properties [7]. In Pakistan, it is useful in the

Manuscript received March 2, 2013; revised June 8, 2013. This work was supported in part by the University of Malaya under Grant UMRG RP025-2012A.

The authors are with Institute of Biological Sciences, Faculty of Science, University of Malaya, 50603 Kuala Lumpur, Malaysia (e-mail: arash_khorasani@yahoo.com,rosna@um.edu.my, brucebanis@yahoo.com, mohajer.ae@gmail.com, raihani_84@yahoo.com, alin@um.edu.my). treatment of sore throat, fever, pneumonia, meningitis and feverish feeling [8]. In some parts of Europe, Red clover is one of the folk medicine for stomach disorders [9]. Native Americans have used Red clover to cure external skin problems and lung illnesses [10]. The importance of Red clover in traditional medicine and antimicrobial effect of phenolic extract of Red clover on the ruminal hyper ammonia-producing bacterium, Clostridium sticklandii [11] prompted us to further evaluate the possible antibacterial and antifungal properties of this plant. The potential uses of in vitro propagated plants as sources for new drugs are still largely unexplored. Based on several investigative studies, a compound produced in an in vivo plant could be produced at the same or different levels or not produced at all in an in vitro grown plant [12]. The variety of compounds produced in in vivo and in vitro plants can show different bioactivity potential. Hence, in this study the antibacterial and antifungal properties of Ethanolic and Methanolic extracts of in vivo grown Red clover were measured and compared with in vitro grown plants and callus tissue of Red clover.

\section{MATERIALS AND METHOD}

\section{A. In Vivo Plant Samples}

Seeds of Trifolium pratense L. were purchased from Stock Seed Farms (Murdock, US) and were cultivated in the growth room of Institute of Biological Science, Faculty of Science, Universiti of Malaya. The complete Red clover plants generated from the cultivated seeds were collected after 6 weeks of germination. The roots of the plants were removed and the aerial parts were used as in vivo plant material.

\section{B. In Vitro Plant Samples}

Some of the purchased seeds were surfaced sterilized by first placing under running tap water for 30 minutes, rinsed once with sterile distilled water and immersed in 50\% Clorox containing 2 drops of Tween 20 for 2 minutes. The seeds were then rinsed five times with sterile distilled water and immersed in $10 \%$ Clorox for one minute. Again the seeds were rinsed five times using sterile distilled water and immersed in $70 \%$ ethanol for 1 minute (under laminar air flow). The seeds were lastly rinsed five times with sterile distilled water and blotted on sterilized filter paper.

The sterilized seeds were then germinated on Murashige and Skoog (MS) medium without any hormones. The in vitro regenerated Red clover after six weeks of culture was used as one of the plant materials in this study.

Callus tissue of Red clover was also produced using MS medium containing $0.5 \mathrm{mg} / 1 \mathrm{BAP}$ and $1 \mathrm{mg} / 1 \mathrm{IBA}$. The six 
-week- old callus was collected as one of the in vitro plant materials/samples.

\section{Extract Preparation}

The plant samples (in vivo and in vitro grown plant as well as callus tissues) were dried in an incubator at $40^{\circ} \mathrm{C}$ and were then ground to produce fine homogenous powder using an electric blender. The fine powder $(3 \mathrm{~g})$ was soaked in $40 \mathrm{ml}$ of $95 \%$ ethanol or Methanol at room temperature in the dark for three days before it was filtered through Whatman ${ }^{\circledR}$ No. 1 filter paper (Whatman International, England). The filtered solutions were then evaporated to dryness by placing them in a water bath at $40^{\circ} \mathrm{C}$ overnight. The plant extracts $(100$ $\mathrm{mg} / \mathrm{ml}$ ) were dissolved in Dimethyl sulfoxide (DMSO) and kept at $4{ }^{\circ} \mathrm{C}$ until required for the experiments.

\section{Antimicrobial Activity Essay}

The antibacterial potential of ethanolic and methanolic extracts of Red clover was studied using the paper disc diffusion method of Kil et al., [13]. Two gram-negative pathogenic bacteria (Escherichia coli and Pseudomonas aeruginosa) and two gram-positive pathogenic bacteria (Staphylococcus aureus and Bacillus cereus) were obtained from the Microbiology Division of Institute of Biological Sciences, University of Malaya and then grown in nutrient broth medium to yield a final concentration of $10^{7}$ colony forming unit $(\mathrm{CFU}) / \mathrm{ml}$. The test bacteria $(0.1 \mathrm{ml})$ were streaked on Mueller Hinton medium plates using sterile cotton swab. Sterilized filter paper discs were soaked in ethanolic and methanolic extracts $(100 \mathrm{mg} / \mathrm{ml})$ and were then placed in the center of test bacteria plates. The plates were incubated for $24 \mathrm{~h}$ and the diameters of the inhibition zones were measured. Tetracycline disc $(30 \mu \mathrm{g})$ and DMSO were used as the positive and negative controls, respectively. All measurement were performed in triplicate and mean values \pm SD were recorded.

\section{E. Antifungal Activity Assay}

Antifungal activity was measured using paper disc diffusion method of Erturk [14]. Twenty $\mathrm{mL}$ of Sabouraud Dextrose Agar (SDA) was poured into each $15 \mathrm{~cm}$ petri dish. The fungal strains used in this study were Aspergillus niger,
Candida albicans and Fusarium verticillioides which were grown in Sabouraud Dextrose Broth at $27^{\circ} \mathrm{C}$ for 48 hours. Growth was adjusted to OD $(600 \mathrm{~nm})$ of 0.1 by dilution with Sabouraud Dextrose Broth. $0.1 \mathrm{~mL}$ of suspension containing approximately $10^{8}$ fungal $/ \mathrm{mL}$ were placed over agar in petri dishes and dispersed using sterile cotton swab. Then sterilized filter paper discs (6 mm diameter) were soaked in ethanolic and methanolic extracts of each sample $(100 \mathrm{mg} / \mathrm{ml})$ and were then placed in the center of test fungal plates. One hundred units of Nystatin were used as a positive control and DMSO as a negative control. Inhibition zones were determined in $\mathrm{mm}$ after incubation at $27^{\circ} \mathrm{C}$ for 72 hours. All experiments were done in triplicate.

\section{RESUlTS AND DisCUSSION}

In the present investigation, the inhibitory effect of ethanolic and methanolic extracts of in vivo, in vitro and callus from Trifolium pratense were evaluated against both fungicidal and bacterial strains. The antimicrobial activity was determined using paper disc diffusion method and summarized in Tables I and II. The antimicrobial potential of the experimental plants were evaluated according to their zone of inhibition against various pathogens and the results (zone of inhibition) were compared with the activity of the standards. The results revealed that all callus, in vivo and in vitro plant extracts are potent antimicrobial against three of the bacteria strains and two fungal strains studied (S.a, B.c, E.c, A.n and C.n). The callus extract showed antimicrobial activities against all microorganisms tested. Among the two solvents extracts studied, methanol extract showed higher degree of inhibition followed by ethanol extract. For all the investigated microorganisms, the callus extract showed maximum antibacterial and antifungal activities. In ethanolic extract, maximum inhibition zone diameter among all the tested microorganisms was obtained in E. coli with diameter of $16 \pm 1.76 \mathrm{~mm}$. Similarly, methanol extract showed maximum inhibition zone with diameter of $16 \pm 1.66 \mathrm{~mm}$ in $B$. cereus and $16 \pm 1.44 \mathrm{~mm}$ in C. albicans.

TABLE I: ANTIMICROBIAL ACTIVITY (INHIBITION ZONE) OF ETHANOLIC EXTRACT OF CALLUS, IN VITRO AND IN VIVO GROWN TRIFOLIUM PRATENSE

\begin{tabular}{|c|c|c|c|c|c|c|c|}
\hline \multirow[t]{3}{*}{ Sample } & \multicolumn{7}{|c|}{ Inhibition Zone (mm) } \\
\hline & \multicolumn{3}{|c|}{ Bacteria strains } & \multicolumn{4}{|c|}{ Fungal strains } \\
\hline & E.c & P.a & S.a & B.c & A.n & C.a & F.v \\
\hline In vivo & $10 \pm 1.3$ & - & $8 \pm 0.76$ & $11 \pm 1.57$ & $7 \pm 0.66$ & $9 \pm 1.57$ & - \\
\hline In vitro & $11 \pm 1.63$ & - & $7 \pm 1.41$ & $14 \pm 0.88$ & $6 \pm 1.4$ & $10 \pm 1.63$ & - \\
\hline Callus & $16 \pm 1.76$ & - & $11 \pm 1.22$ & $15 \pm 1.54$ & $10 \pm 1.33$ & $13 \pm 0.57$ & $4 \pm 0.36$ \\
\hline $\begin{array}{l}\text { Tetra } \\
\text { cycline }\end{array}$ & $24 \pm 1.6$ & $11 \pm 1.33$ & $20 \pm 0.57$ & $21 \pm 0.88$ & $\mathrm{NT}^{*}$ & NT & NT \\
\hline Nystatin & NT & NT & NT & NT & $20 \pm 2.5$ & $27 \pm 2.6$ & $16 \pm 1.57$ \\
\hline
\end{tabular}

E.c (Escherichia coli); P.a (Pseudomonas aeruginosa); S.a (Staphylococcus aureus); B.c (Bacillus cereus); A.n (Aspergillus niger); C.a (Candida albicans); F.v (Fusarium verticillioides)

*NT (not tested) 


\begin{tabular}{|c|c|c|c|c|c|c|c|}
\hline \multirow[t]{3}{*}{ Sample } & \multicolumn{7}{|c|}{ Inhibition Zone (mm) } \\
\hline & \multirow[b]{2}{*}{ E.c } & \multicolumn{2}{|c|}{ Bacteria strains } & \multirow[b]{2}{*}{ B.c } & \multicolumn{3}{|c|}{ Fungal strains } \\
\hline & & P.a & S.a & & A.n & C.a & F.v \\
\hline In vivo & $11 \pm 1.57$ & - & $6 \pm 1.41$ & $13 \pm 1.41$ & $8 \pm 1.33$ & $7 \pm 1.88$ & - \\
\hline In vitro & $13 \pm 1.88$ & - & $9 \pm 0.57$ & $13 \pm 1.57$ & $9 \pm 0.88$ & $12 \pm 0.33$ & - \\
\hline Callus & $15 \pm 0.66$ & $7 \pm 0.88$ & $14 \pm 1.33$ & $16 \pm 1.66$ & $13 \pm 0.66$ & $16 \pm 1.44$ & $7 \pm 1.33$ \\
\hline $\begin{array}{l}\text { Tetra } \\
\text { cycline }\end{array}$ & $26 \pm 1.57$ & $14 \pm 0.88$ & $21 \pm 1.76$ & $25 \pm 1.76$ & $\mathrm{NT}^{*}$ & NT & NT \\
\hline Nystatin & NT & NT & NT & NT & $23 \pm 1.66$ & $28 \pm 1.77$ & $18 \pm 1.2$ \\
\hline
\end{tabular}

E.c (Escherichia coli); P.a (Pseudomonas aeruginosa); S.a (Staphylococcus aureus); B.c (Bacillus cereus); A.n (Aspergillus niger); C.a (Candida albicans); F.v (Fusarium verticillioides)

*NT (not tested)

The present study is in agreement with the previous reports on higher antimicrobial activities of methanolic plant extracts than ethanolic [15]-[17]. From the results, it is clear that the effectiveness of the extracts largely depends on the type of solvent used.

The results of this study also confirmed the study of Gami and Kothari [18], Dhabhi et al., [19] and Shafique et al., [20] whereby, they showed that antimicrobial activities of callus and in vitro grown plants were higher than in vivo grown plants. The higher antimicrobial activity of the callus extract might be either related to the production of a compound produced in only undifferentiated callus cells or may be produced in higher amounts in these cells when compared to differentiated cells. Several quantitative estimations and studies showed that the production of biocompounds can vary between differentiated and undifferentiated plant cells. For example, Tanwer et al., [21] reported that calli of $S$. acemella produced a higher amount of sugars when compared with stem, leaves and roots of the intact plant. Jana and Shekhawat [22] also showed that the callus cells of $A$. graveolens produced saponins, while the in vitro leaf cells were not able to produce the same compound.

In conclusion, the present investigation revealed that the callus extract of Trifolium pratense contains higher antimicrobial activities than in vivo and in vitro grown plants. Although this potential is significantly smaller than positive control, these findings indicate that in vitro culture or even undifferentiated cells of callus can improve the quality of plant materials for medicinal uses.

\section{REFERENCES}

[1] C. E. Evans, A. Banso, and O. A. Samuel, "Efficacy of some nupe medicinal plants against Salmonella typhi: an in vitro study," Journal of Ethnopharmacology, vol. 80, pp. 21-24, 2002.

[2] K. Saxena, "Antimicrobial screening of selected medicinal plants from India," Journal of Ethnopharmacology, vol. 58, pp. 75-83, 1997.

[3] C. E. Piersen, N. L. Booth, Y. Sun, W. Liang, J. E. Burdette, R. B. Breemen, S. E. Geller, C. Gu, S. Banuvar, L. P. Shulman, J. L. Bolton, and N. R. Farnsworth, "Chemical and biological characterization and clinical evaluation of botanical dietary supplements: a phase I red clover extract as a model," Current Medicinal Chemistry, vol. 11, pp. 1361-1374, 2004.

[4] C. J. Kolodziejczyk, "Trifolium species-derived substances and extracts--biological activity and prospects for medicinal applications,'
Journal of Ethnopharmacol, vol. 143, no. 1, pp. 14-23, 2012.

[5] L. Zoric, L. Merkulov, J. Lukovic, and P. Boza, "Comparative analysis of qualitative anatomical characters of Trifolium L. (Fabaceae) and their taxonomic implications: preliminary results," Plant Systematics and Evolution, vol. 298, no. 1, pp. 205-219, 2012.

[6] N. J. Enqelmann, A. Reppert, G. Yousef, R. B. Roqers, and M. A. Lila, "In vitro production of radiolabeled Red clover (Trifolium pratense) isoflavones," Plant Cell, Tissue and Organ Culture, vol. 98, no. 2, pp. 147-156, 2009.

[7] K. A. Viqar, A. Q. Uddin, I. Shukla, and A. Ali khan, "Antibacterial activity of leaves extracts of Trifolium alexandrinum Linn. Against pathogenic bacteria causing tropical diseases," Asian Pacific Journal of Tropical Biomedicine, pp. 189-194, 2012.

[8] S. W. Khan and S. Khatoon, "Ethnobotanical studies on some useful herbs of Haramosh and Bugrote Valley in Gilgit, northern areas of Pakistan," Pakistan Journal of Botany, vol. 40, pp. 3-58, 2008.

[9] B. Mustafa, A. Hajdari, F. Krasniqi, E. Hoxha, H. Ademi, and A. Pieroni, "Medical ethnobotany of the Albanian Alps in Kosovo," Journal of Ethnobiology and Ethnomedicine, vol. 8, no. 6, pp. 1-14, 2012.

[10] T. Sabudak, N. Guler, "Trifolium L. - a review on its phytochemical and pharmacological profile," Phytotherapy Research, vol. 23, pp. 439-446, 2009.

[11] M. Flythe and I. Kagan, "Antimicrobial effect of Red clover (Trifolium pratense) phenolic extract on the ruminal hyper ammoniaproducing bacterium, Clostridium sticklandii," Curr Microbiol, vol. 61, pp. 125-131, 2010.

[12] R. Verpoorte, A. Contin, J. Memelink, "Biotechnology for the production of plant secondary metabolites," Phytochem. Rev., vol. 1, no. 1, pp. 13-25, 2002.

[13] H. Y. Kil, E. S. Seong, B. K. Ghimire, I. M. Chung, S. S. Kwon, E. J. Goh, K. Heo, M. J. Kim, J. D. Lim, D. Lee, and C. Y. Yu, "Antioxidant and antimicrobial activities of crude sorghum extract," Food Chem, vol. 115, no. 4, pp. 1234-1239, 2009.

[14] O. Erturk, "Antibacterial and antifungal activity of ethanolic extracts from eleven spice plants," Biologia, Bratislava, vol. 61, no. 3, pp. 275-278, 2006.

[15] J. N. Eloff, "Which extractant should be used for the screening and isolation of antimicrobial components from plants," Journal of Ethnopharmacol, vol. 60, pp. 1-8, 1998.

[16] H. Durmaz, E. Sagun, Z. Tarakci, and F. Ozgokce, “Antibacterial activities of Allium vineale, Chaerophyllum and Prangos ferulaceae," African J. Biotechnol., vol. 5, no. 19, pp. 1795- 1798, 2006.

[17] M. Soniya, T. Kuberan, S. Anitha, and P. Pankareswari, "In vitro antibacterial activity of plant extracts against gram positive and gram negative pathogenic bacteria," International Journal of Microbiology and Immunology Research, vol. 2, no. 1, pp. 1-5, 2013.

[18] B. Gami and I. L. Kothari, "Antioxidant and antimicrobial activity of In vivo and In vitro grown plants of Phyllanthus niruri L.," International Journal of Pharma and Bio Sciences, vol. 2, no. 2, pp. 78-89, 2011.

[19] K. Dhabhai, S. Bhargav, and A. Batra, "In vitro and In vivo antibacterial comparative study in Acacia nilotica L.," International Journal of Pharmacy and Pharmaceutical Sciences, vol. 4, no. 1, pp. 174-175, 2012. 
[20] M. Shafiqua, K. S. Jabeen, and K. N. Habib, "Comparative study for antibacterial potential of In vitro and In vivo grown Ocimum basilicum L. plant extracts," Pakistan Journal of Biochemistry and Molecular Biology, vol. 44, no. 3, pp. 113-117, 2011.

[21] B. S. Tanwer, R. Choudhary, and R. Vijayvergia, "In vitro and in vivo comparative study of primary metabolites and antioxidant activity in Spilanthes acmella Murr," Int. J. Biotechnol. Biochem. vol. 6, no. 5, pp. 819-825, 2010.

[22] S. Jana and G. S. Shekhawat, "Phytochemical analysis and antibacterial screening of in vivo and in vitro extracts of Indian medicinal herb: Anethum graveolens," Res. J. Med. Plant., vol.4, pp. 206-212, 2010.

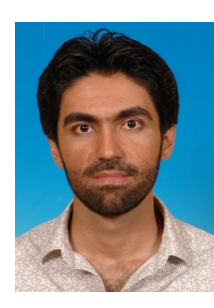

Arash Khorasani Esmaeili was born on 02/01/1983 in Iran. He was the Master of Science in Plant Biotechnology in the Institute of Biological Sciences, Faculty of Science in the University of Malaya. He was the Bachelor of Science in Agricultural Engineering in the Faculty of Agriculture, Shahid Bahonar University of Kerman, Iran. He was the research assistant at Faculty of Science in the University of Malaya from November, 2011 to April, 2012. He had his Internship at International University College of Technology TwinTech from April, 2011 to September, 2011. He was the research assistant at Faculty of Science in the University of Malaya from April, 2009 to July, 2010. At the moment he is a Ph.D student in plant biotechnology, university of Malaya. 